\title{
CONSTRAINTS PERCEIVED BY FARMERS IN ADOPTION OF SERICULTURE PRODUCTION TECHNOLOGIES IN JORHAT DISTRICT OF ASSAM
}

\author{
D. HATIBARUAH ${ }^{1}$, D. BORAH ${ }^{2}$ \& N. SAIKIA ${ }^{3}$ \\ ${ }^{1,3}$ Agriculture Student, Department of Sericulture, FA, AAU, India \\ ${ }^{2}$ Assistant Professor, College of Sericulture, CS, AAU, India
}

\begin{abstract}
The study focused on constraints perceived by farmers in adoption of Sericulture Production technologies in Jorhat district of Assam. Because of non awareness of improved sericulture technologies as well as poor living conditions, the adoption level of sericulture technologies among the farmers of Jorhat district is very limited and there is still a gap in dissemination and adaptation of improved sericultural technologies in pre and post cocoon sector among the farmers for growth and development of sericulture in acreage of food plants, rearing of silkworm and production and productivity of cocoon and silk. The constraints faced were lack of knowledge about training and pruning of host plants in adoption of host plant cultivation technology, improper maintenance of temperature and humidity, lack of regular technical guidance, non availability of protected storage house in villages, non availability of suitable and big market nearby villages, lack of improved reeling and spinning machine, lack of awareness on improved technology adoption, high cost of rearing and other sericulture production technologies and lack of timely guidance etc. The present findings can facilitate government and different organizations for developing strategies for proper utilization of accessible resources and it may be useful to the extension functionaries in addressing the constraints in a greater depth and develop better strategies for increasing the adoption level of silkworm rearers.
\end{abstract}

KEYWORDS: Constraints, Sericulture Farmers, Adoption Level \& Sericulture Production Technology

Received: Jul 20, 2021; Accepted: Aug 10, 2021; Published: Aug 20, 2021; Paper Id.: IJASRDEC202120

\section{INTRODUCTION}

Sericulture is an agro-based industry and one of the prominent enterprises and it involves a series of on-farm, offfarm and industrial activities. India occupies second place in the world in the production of silk and also consumes the highest quantity of raw silk and provides employment to 8.51 million people in the country. Sericulture is predominantly practiced in North East India by small marginal farmers. Assam enjoys a unique distinction by producing all the four commercial natural silks viz., muga, eri, mulberry and tasar. The Jorhat district of Assam plays a major role in silk production. Sericulture has been practiced traditionally in the district and a large portion of rural people earn their livelihood from the sericulture sector. Presently, the culture is practiced in about 492 serivillages of the district covering an area of 638 hectors under silkworm food plants cultivation with the engagement of nearly 10 thousand families in various sericultural activities. The potential of sericulture remains unexplored because of certain proportion of some difficulties still remained with the existing conventional practice of production. A wide gap exists between the recommended sericultural technology and the adoption of practices by the farmers. The Department of Sericulture, Govt. of Assam has created sufficient infrastructure for sericulture development with state fund and also financial support of Govt. of India through Central Silk Board. Loans, grants, subsidies and other inputs are generously distributed to the rearers through various developmental schemes. Despite 
all these strategies, the majority of the silkworm rearers are still inclined to follow their traditional practices for silkworm culture and production of silk. Effective extension intervention may aid the process of intensification for full scale commercialization of silk production by facilitating the adoption of recommended package of practices.

Keeping in view the above facts and importance, the study was undertaken with the following objective.

- To ascertain the constraints perceived by the farmers in adoption of sericulture production technology.

\section{METHODOLOGY}

The present study was undertaken in the purposively selected Jorhat and Majuli (undivided) district of Assam as sericulture has been practiced traditionally in Jorhat and Majuli (undivided) district and a large portion of rural people earn their livelihood from the sericulture sector. Twenty sericulture farmers were selected randomly from each of the villages namely Tamulbari, Pangiria, Kochukhat and Lahong Kachari Gaon from Jorhat district, Kumarbari and Chawrekia Gaon from Majuli (undivided) district, thus a sample size of 120 respondents were selected. The respondents were interviewed with the help of a structured schedule prepared for the purpose. According to the objective of the present study, the data collected were subjected to statistical analysis viz., simple frequencies, percentage and rank orders.

\section{RESULTS AND DISCUSSIONS}

The various constraints and difficulties faced by the silkworm rearers are presented in the following heads. A number of constraints were faced by the rearers during the rearing, reeling and spinning process.

\section{Constraints in Adoption of Recommended Host Plant Cultivation Technology}

The sericulture farmers were enquired regarding the constraints which they faced in the adoption of recommended host plant cultivation technology in sericulture. Data presented in (Table1) revealed that the majority (83.33\%) of the respondents were of opinion about lack of knowledge about training and pruning of host plant ranked first. While other constraints faced by the respondents were lack of irrigation facilities (66.66\%) ranked second, lack of improved variety (49.16\%) ranked third, high cost of fertilizer, insecticide and fungicide (47.50\%) ranked fourth, non availability of plants for propagation (43.33\%) ranked fifth and small size of land holding (34.16\%) ranked as sixth respectively. Raychoudhary (1992) found that non availability of irrigated land and irrigation facilities were major constraints in mulberry cultivation.

Table 1: Rank wise Distribution of Constraints Faced by the Respondents in the Adoption of Host Plant Cultivation Technology $\mathbf{n}=\mathbf{1 2 0}$

\begin{tabular}{|l|c|c|c|}
\hline \multicolumn{1}{|c|}{ Constraints } & Frequency & $\begin{array}{c}\text { Percentage } \\
\mathbf{( \% )}\end{array}$ & Rank \\
\hline Lack of improved variety & 59 & 49.16 & III \\
\hline Small size land holding & 41 & 34.16 & VI \\
\hline Lack of knowledge about training and pruning of host plant & 100 & 83.33 & I \\
\hline Non availability of plants for propagation & 52 & 43.33 & V \\
\hline High cost of fertilizer, insecticide and fungicide & 57 & 47.50 & IV \\
\hline Lack of irrigation facilities & 80 & 66.66 & II \\
\hline
\end{tabular}

\section{Constraints in Adoption of Recommended Silkworm Rearing Technology}

Distribution of constraints faced by the respondents in adoption of recommended silk worm rearing technology are enlisted in table 2. It is evident from the results that under Silkworm rearing technology constraints, the majority (95.83\%) of the 
respondents were of opinion about improper temperature and humidity during incubation time of eggs ranked as first. While other constraints faced by the respondents were lack of knowledge about concentration of the disinfectant $(73.33 \%)$ ranked second, non availability of proper rearing house (67.50\%) ranked third, non availability of equipments (nylon net, brushing bag) for silkworm rearing (66.66\%) ranked fourth, Inadequate silkworm rearing equipment $(51.66 \%)$ ranked fifth, Lack of supply of disease free layings (DFLs) from govt. sources (50.00\%) ranked sixth, Lack of knowledge about timely brushing of silkworms $(40.00 \%)$ ranked seventh and Difficulty in maintaining freshness and quality leaves for feeding of larvae (34.16\%) ranked as eighth respectively.

Table 2: Rank wise Distribution of Constraints Faced by the Respondents in Adoption of Recommended Silkworm Rearing Technology $n=120$

\begin{tabular}{|l|c|c|c|}
\hline \multicolumn{1}{|c|}{ Constraints } & Frequency & $\begin{array}{c}\text { Percentage } \\
(\%)\end{array}$ & Rank \\
\hline Lack of knowledge about timely brushing of silkworms & 48 & 40.00 & VII \\
\hline Inadequate silkworm rearing equipment & 62 & 51.66 & V \\
\hline Lack of supply of disease free layings (DFLs) from govt. sources & 60 & 50.00 & VI \\
\hline $\begin{array}{l}\text { Non availability of equipments (nylon net, brushing bag) for silkworm } \\
\text { rearing }\end{array}$ & 80 & 66.66 & IV \\
\hline Lack of knowledge about concentration of the disinfectant & 88 & 73.33 & II \\
\hline Improper temperature and humidity during incubation time of eggs & 115 & 95.83 & I \\
\hline $\begin{array}{l}\text { Difficulty in maintaining freshness and quality leaves for feeding of } \\
\text { larvae }\end{array}$ & 41 & 34.16 & VIII \\
\hline Non availability of proper rearing house & 81 & 67.50 & III \\
\hline
\end{tabular}

\section{Constraints Related to Disease and Pest Control of Silkworms}

It is observed from table 3 that lack of regular technical guidance was the major constraint faced by the majority (84.16\%) of the respondents in disease and pest control of the silkworm ranked first. The other important constraints regarding disease and pest control faced by the respondents were lack of knowledge about identification of disease and pest (81.66\%) ranked second, frequent and high incidence of disease and pest (65.00\%) ranked third and unavailability of insecticide and fungicide on proper time (62.50\%) ranked as fourth etc. More or less similar findings were reported by Sakthivel et al. (2012).

Table 3: Rank wise Distribution of Constraints Faced by the Respondents in Disease and Pest Control $\mathbf{n}=120$

\begin{tabular}{|l|c|c|c|}
\hline \multicolumn{1}{|c|}{ Constraints } & Frequency & $\begin{array}{c}\text { Percentage } \\
(\boldsymbol{\%})\end{array}$ & Rank \\
\hline Lack of knowledge about identification of disease and pest & 98 & 81.66 & II \\
\hline Unavailability of insecticide and fungicide on proper time & 75 & 62.50 & IV \\
\hline Frequent and high incidence of disease and pest & 78 & 65.00 & III \\
\hline Lack of regular technical guidance & 101 & 84.16 & I \\
\hline
\end{tabular}

\section{Constraints Related to Storage of Cocoon}

It is evident from Table 4 that the majority of the respondents (95.83\%) as regards to storage of the cocoon were of opinion about non availability of protected storage house in the village as their major constraints ranked as first, followed by 70.00 per cent of the respondents were having lack of own storage house ranked as second, loss of cocoon in the storage by rates (60.00\%) ranked third, high cost of storage house (55.00\%) ranked fourth and difficulties in grading of cocoon (53.33\%) ranked as fifth respectively. 
Table 4: Rank wise Distribution of Constraints Faced by the Respondents in Storage of Cocoon $n=120$

\begin{tabular}{|l|c|c|c|}
\hline \multicolumn{1}{|c|}{ Constraints } & Frequency & $\begin{array}{c}\text { Percentage } \\
(\boldsymbol{\%})\end{array}$ & Rank \\
\hline Lack of own storage house & 84 & 70.00 & II \\
\hline High cost of storage house & 66 & 55.00 & IV \\
\hline Difficulties in grading of cocoon & 64 & 53.33 & V \\
\hline Loss of cocoon in storage by rates & 72 & 60.00 & III \\
\hline Non availability of protected storage house in village & 115 & 95.83 & I \\
\hline
\end{tabular}

\section{Constraints Related to Marketing of Cocoons}

Marketing is the process for promotion and selling products. Data presented in table 5 indicated that the majority of the respondents $(71.66 \%)$ were opinioned that non availability of suitable and big market nearby village is the major constraint in the marketing of cocoons produced by them ranked as first. In addition, the other constraints related to the marketing of cocoon were fluctuation in price of cocoon (62.50\%), Long distance of trading units for sale of cocoon (60.00\%), involvement of mediator in marketing $(49.16 \%)$ and high cost of transportation $(40.00 \%)$ as ranked second, third, fourth and fifth respectively.

Table 5: Rank wise Distribution of Constraints Faced by the Respondents in Marketing of Cocoons $n=120$

\begin{tabular}{|l|c|c|c|}
\hline \multicolumn{1}{|c|}{ Constraints } & Frequency & $\begin{array}{c}\text { Percentage } \\
(\boldsymbol{\%})\end{array}$ & Rank \\
\hline Long distance of trading units for sale of cocoon & 72 & 60.00 & III \\
\hline Involvement of mediator in marketing & 59 & 49.16 & IV \\
\hline Non availability of suitable and big market nearby village & 86 & 71.66 & I \\
\hline Fluctuation in price of cocoon & 75 & 62.50 & II \\
\hline High cost of transportation & 48 & 40.00 & V \\
\hline
\end{tabular}

\section{Constraints Relates to Processing of Cocoons for Yarn Production}

It is observed from the data presented in Table 6 that regarding the processing of cocoon, the majority of the respondents $(78.33 \%)$ were facing problems due to lack of improved reeling and spinning machine and considered as their major constraints ranked first, followed by 72.50 per cent respondents facing problems due to high cost of reeling and spinning machines ranked second, lack of technical guidance (71.66\%), lack of technical man (43.33\%) and high remuneration of skilled realer $(40.00 \%)$ ranked as third and fourth and fifth respectively. Similar constraints in processing of cocoons for yarn production were also reported by Geetha and Geetha Devi (2008) in their studies.

Table 6: Rank wise Distribution of Constraints Faced by the Respondents in Processing of Cocoons for Yarn Production $n=120$

\begin{tabular}{|l|c|c|c|}
\hline \multicolumn{1}{|c|}{ Constraints } & Frequency & $\begin{array}{c}\text { Percentage } \\
(\boldsymbol{\%})\end{array}$ & Rank \\
\hline Lack of technical guidance & 86 & 71.66 & III \\
\hline Lack of improved reeling and spinning machine & 94 & 78.33 & I \\
\hline Lack of technical man & 52 & 43.33 & IV \\
\hline High remuneration of skilled realer & 48 & 40.00 & V \\
\hline High cost of reeling and spinning machine & 87 & 72.50 & II \\
\hline
\end{tabular}




\section{Personal Constraints}

It is evident from Table 7 that with regards to personal constraints, the majority $(70.00 \%)$ of the respondents were facing problems due to lack of awareness on technology adoption ranked first, followed by lack of capital $(60.00 \%)$ ranked second, lack of formal education (47.50\%) as third, large size family (39.16\%) as fourth, lack of self confidence (44.16\%) as fifth, lack of communication with other farmers (34.16\%) as sixth and lack of prior experience (31.66\%) ranked as seventh respectively. Knowledge is the primitive factor for non-adoption of improved packages of practices which was reported by (Shinghivi et al., 1994 and Puttaswamy, 1977).

Table 7: Rank wise Distribution of Personal Constraints Faced by the Respondents n=120

\begin{tabular}{|l|c|c|c|}
\hline \multicolumn{1}{|c|}{ Constraints } & Frequency & $\begin{array}{c}\text { Percentage } \\
(\boldsymbol{\%})\end{array}$ & Rank \\
\hline Lack of formal education & 57 & 47.50 & III \\
\hline Large size family & 47 & 39.16 & V \\
\hline Lack of self confidence & 53 & 44.16 & IV \\
\hline Lack of capital & 72 & 60.00 & II \\
\hline Lack of awareness on technology adoption & 84 & 70.00 & I \\
\hline Lack of communication with other farmers & 41 & 34.16 & VI \\
\hline Lack of prior experience & 38 & 31.66 & VII \\
\hline
\end{tabular}

\section{Socio Economic Constraints}

Data presented in Table 8 revealed that under socio economic constraints, the majority (76.66\%) of the respondents were of opinion about high cost of rearing equipments and other sericulture production technologies ranked as first. While other socio-economic constraints faced by the respondents were scarcity of labour during harvesting $(64.16 \%)$ as second, high cost of planting material and their management $(46.66 \%)$ as third, lack of glamour (45.00\%) as fourth, unavailability of sufficient subsidy for rearing, reeling and spinning $(41.66 \%)$ as fifth, lack of respect towards rearing $(40.83 \%)$ as sixth and high labour wages (38.33\%) ranked as seventh respectively.

Table 8: Rank wise Distribution of Socio-Economic Constraints Faced by the Respondents $\mathbf{n = 1 2 0}$

\begin{tabular}{|c|c|c|c|}
\hline Constraints & Frequency & $\begin{array}{c}\text { Percentage } \\
(\%)\end{array}$ & Rank \\
\hline Scarcity of labour during harvesting & 77 & 64.16 & II \\
\hline High labour wages & 46 & 38.33 & VII \\
\hline High cost of rearing equipment and other sericulture production technologies & 92 & 76.66 & I \\
\hline Unavailability of sufficient subsidy for rearing, reeling and spinning & 50 & 41.66 & $\mathrm{~V}$ \\
\hline High cost of planting material and their management & 56 & 46.66 & III \\
\hline Lack of respect towards rearing & 49 & 40.83 & VI \\
\hline Lack of glamour & 54 & 45.00 & IV \\
\hline
\end{tabular}

\section{Other Constraints (Related to Institutional and Transportation)}

It is observed from Table 9 that incase of other constraints, the majority $(85.00 \%)$ of the respondents were of opinion that lack of timely guidance ranked first, followed by lack of proper incentives from any govt. / NGOs (66.66\%) ranked second, insufficient training facilities $(65.83 \%)$ as third, lack of frequent contact with extension personal $(53.33 \%)$ as fouth, non availability of information on proper time $(40.00 \%)$, non availability of own vehicle $(36.66 \%)$ and poor transportation (28.33\%) ranked as fifth, sixth and seventh respectively. 
Table 9: Rank wise Distribution of other Constraints Faced by Respondents n=120

\begin{tabular}{|l|c|c|c|}
\hline \multicolumn{1}{|c|}{ Constraints } & Frequency & $\begin{array}{c}\text { Percentage } \\
(\boldsymbol{\%})\end{array}$ & Rank \\
\hline Lack of proper incentives from any govt./NGOs & 80 & 66.66 & II \\
\hline Insufficient training facilities & 79 & 65.83 & III \\
\hline Lack of frequent contact with extension personal & 64 & 53.33 & IV \\
\hline Non-availability of information on proper time & 48 & 40.00 & V \\
\hline Non availability of own vehicle & 44 & 36.66 & VI \\
\hline Poor transportation & 34 & 28.33 & VII \\
\hline Lack of timely guidance & 102 & 85.00 & I \\
\hline
\end{tabular}

The results of the current investigation find support with the findings of Singh et al. (1998) who observed constraints like marketing of cocoon, irrigation of mulberry plants and inconvenience of family labour to adopt such technologies. Rajashekaraiah (1979) reported that marketing of cocoon is the main constraint faced by the farmers, so there is a great need that govt. agencies should develop irrigation facilities and develop a sound marketing system for silk products to promote the sericulture business.

\section{CONCLUSIONS}

It was observed that lack of knowledge about training and pruning of host plants in the adoption of host plant cultivation technology, improper maintenance of temperature and humidity, lack of regular technical guidance, non availability of protected storage house in villages, non availability of suitable and big market nearby villages, lack of improved reeling and spinning machine, lack of awareness on improved technology adoption, high cost of rearing equipments and other sericulture production technologies and lack of timely guidance are the major constraints faced by the farmers of Jorhat district for the adoption of improved technologies in sericulture. So considering the above facts suggestions were like knowledge about training and pruning in host plants should be provided, fertilizers, insecticides and fungicides should be provided at subsidy rates, disease-free layings (DFLs) should be available in desired quantity on time from govt. sources, all the required facilities should be provided on proper time and also specific training should be provided to the identification of disease and pests and adoption of improved sericultural technologies.

\section{REFERENCES}

1. Geetha, G.S. and Geetha Devi, R.G. (2008). Technology adoption and training needs of sericulture farmers - A case study NGO. Indian J. Agric. Res. 43(3): 157-163.

2. Puttaswamy, T. (1977). Knowledge, adoption and attitude of small farmers towards mixed farming in Sira and Anekal taluks. M.Sc. (Agri) Thesis, University of Agricultural Sciences, Bangalore, India.

3. Raychoudhary, S. (1992). Improving the mulberry sericulture in the Sikkim hills. Indian Silk, 30(9): 18-20.

4. Rajashekaraiah (1979). A study on the knowledge and adoption of selected recommended practices of silkworm rearing by small and big farmers of Kanakpura Tluka, Bangalore district. M.Sc. (Ag.) Thesis, University of Agricultural Sciences, Bengaluru, Karnataka (India). p. 76.

5. Sakthivel, N.; Kumaresan P.; Qadri, S.M.H.; Ravikumar, J. and Balakrishna, R. (2012). Adoption of integrated pest management practices in sericulture - A case study in Tamil Nadu. J. Biopest, 5: 212-215. 
6. Shinghivi, N. R.; Rao, M. K. S.; Rao, Y. R. M.; Iyengar, M. N. and Datta, R. K. (1994). Knowledge level and adoption of new sericulture technology by farmers in Hunsur taluk, Mysore district. Karnataka state: An evaluation. Indian Journal of Sericulture, 33(2): 48-55.

7. Singh, K. A.; Jagadeswar, R. and Hussain, S. A. (1998). Constraints in cultivation of mulberry and silkworm rearing. Maharashtra J. Extn. Edu. 17: 344-348.

8. Singh, Harjeet, and Ravneet Kour. "Rearing Performance of Bivoltine Hybrids of the Silkworm." International Journal of Applied and Natural Sciences (IJANS) 7 (2018): 1-4.

9. Paul, Amrit, and Sanjeeb K. Jena. "Viability and Prospects of Muga Silk Cultivation in the Lakhimpur District of Assam." (2017). International Journal of Business and General Management (IJBGM) 6.4, Jun - Jul 2017; 33-44

10. Singh, Ningthoujam Tiken, Harjeet Singh, and Mutum Shyamkesho Singh. "Evaluation of Different Fungicides and Plant Extracts for Management of Leaf Rust of Quercus Serrata Thunb Caused by Cronartium Quercuum Miyabe Ex Shirai." International Journal of Applied and Natural Sciences (IJANS) 7 (2018): 25-32.

11. Geetha, T., C. A. Mahalingam, and N. Murugan. "Impact of rearing of mulberry silkworm (Bombyx mori L) on thrips (Pseudodendrothrips mori Niwa) infested mulberry leaves." International Journal of Agricultural Science and Research (IJASR) 5.3 (2015): 81-84. 
